\title{
Rede admirável epidural rostral e caudal e suas fontes de suprimento sangüíneo em javali (Sus scrofa scrofa)
}

\author{
The rostral and caudal epidural rete mirabile and its blood supply source \\ in wild boar (Sus scrofa scrofa)
}

\author{
João Cesar Dias Oliveira ${ }^{1}$ Rui Campos ${ }^{2}$
}

\section{RESUMO}

Este trabalho visou descrever e sistematizar, no javali, as fontes que supriram as redes admiráveis epidurais rostrais e caudais (RAER e RAEC) responsáveis pela irrigação do encéfalo. Foram coletadas 32 cabeças, das quais 30 foram injetadas com látex 603, e duas com resina odontológica, pelas artérias carótidas comuns. A artéria (A.) carótida comum dividiuse nas artérias carótidas interna e externa. A A. carótida interna emitiu as artérias: occipital e condilar, ramificando-se na formação da RAER, como sua principal fonte. A A. carótida externa continuou-se como A. maxilar, que emitiu as artérias meníngea média e oftálmica externa, as quais cooperaram com ramos para a $R A E R$. As redes rostrais anastomosaram-se em rede, formando um " $H$ ", e delas confluíram as artérias carótidas do cérebro. Cada RAEC foi constituída principalmente pela A. occipital, com cooperação das artérias condilar e vertebral, e originaram a A. basilar.

Palavras-chave: rete mirabile, vascularização encefálica, artiodáctilos, javali, sistema circulatório.

\section{ABSTRACT}

This work aims to describe and systematize, in the wild boar, the sources that supply the rostral and caudal epidural rete mirabile, responsible for the encephalon irrigation. 32 wild boar heads were used, 30 of them injected with latex 603, and the other 2 injected with odontological resin through the common carotid arteries. The common carotid artery divided into the internal and external carotid arteries. The internal carotid artery emitted the occipital and the condilar arteries and branched to form the rostral epidural rete mirabile, as its main source. The external carotid artery continuing as the maxillary artery from which emerge the middle meningeal artery and the external ophthalmic artery that cooperate with branches to the rostral epidural rete mirabile. The right and the left rostral rete mirabilis anastomosed to each other forming a net, that seems like an " $H$ ", and from them the brain carotid arteries were originated. The right and the left caudal epidural rete mirabilis were mainly formed by the occipital artery with the cooperation of the condilar and the vertebral arteries and originating the basilar artery.

Key words: rete mirabile, encephalic vascularization, artiodactyls, wild boar, circulatory system.

\section{INTRODUÇÃO}

A irrigação sangüínea para o encéfalo apresenta uma considerável variação entre as espécies animais. Tais modificações estão relacionadas com as fontes de suprimento sangüíneo e com a multiplicidade de arranjos das artérias que se distribuem na região do sistema nervoso central. Dados sobre estas fontes de suprimento revelaram-se contraditórios e escassos no suíno ou inexistentes no javali. DANIEL et al. (1953); BOURDELE \& BRESSOU (1964); McCLURE \& DELLMANN (1965), GILLILAN (1974) e McGRATH (1977) descreveram apenas a rede admirável epidural rostral, também chamada por alguns autores de "rede carótida" ou "rede admirável carótida". Entretanto, a existência de uma rede admirável epidural caudal é referida apenas por GHOSHAL (1981); NANDA (1981) e GHOSHAL \& KHAMAS (1985). JABLONSKI et al. (1989)

${ }^{1}$ Médico Veterinário, Professor Assistente, Departamento de Morfologia, Centro de Ciências da Saúde (CCS), Universidade Federal de Santa Maria (UFSM), Doutorando em Anatomia Animal na Universidade Federal do Rio Grande do Sul (UFRGS). Depto Morfologia, CCS, UFSM, Campus Universitário, 97105-900, Santa Maria, RS. E-mail: jcd.oliveira@smail.ufsm.br . Autor para correspondência.

${ }^{2}$ Médico Veterinário, Doutor, Professor Adjunto, Departamento de Ciências Morfológicas, Instituto de Ciências Básicas da Saúde, UFRGS. E-mail: rcampos@vortex.ufrgs.br 
estudaram as artérias da base do encéfalo no javali sem citar as fontes formadoras das redes, assim como FERREIRA (1998) em suínos; fatos estes que justificam a presente pesquisa. Este estudo objetivou a sistematização das fontes sanguiíneas supridoras das redes admiráveis epidurais rostral e caudal em Sus scrofa scrofa (Javali).

\section{MATERIAL E MÉTODOS}

Para a realização desta pesquisa, utilizaramse 32 cabeças, com segmento de pescoço seccionado na altura da terceira vértebra cervical de Sus scrofa scrofa (Javali), com idade aproximada de seis meses, sendo 12 machos e 20 fêmeas, provenientes de criatórios e abatedouro (Frigorífico Bassanense de Nova Bassano-RS), autorizados pelo Instituto Brasileiro do Meio Ambiente e dos Recursos Naturais Renováveis (IBAMA).

Os animais foram dessensibilizados por eletro-choque, seguido de exangüinação pelas veias jugulares e artérias carótidas comuns, próximos à entrada do tórax, de acordo com a rotina normal de abate. As artérias carótidas comuns foram canuladas, e o sistema lavado com, no mínimo, $600 \mathrm{ml}$ de solução salina resfriada associada a $2500 \mathrm{UI}$ de heparina ${ }^{\mathrm{a}}$ por animal.

O sistema arterial de 30 espécimes foi preenchido com látex $603^{\mathrm{b}}$ corado em vermelho com corante específico ${ }^{c}$, utilizados para a sistematização. As peças permaneceram, no mínimo por uma hora, em água corrente para polimerização do látex. Após, a pele foi removida e uma janela óssea aberta na abóbada craniana, acompanhada da abertura da duramáter. As amostras foram imersas em formol a $20 \%$, pelo período de sete dias, para fixação. Para a confecção de moldes, duas amostras foram injetadas com resina odontológica ${ }^{\mathrm{d}}$ corada com pigmento específico e submetidas à maceração, em torno de seis meses, para observações complementares. Nos exemplares injetados com látex, procedeu-se à dissecção dos ramos das artérias carótidas comuns, com ênfase para os ramos colaterais que se dirigiam até as redes admiráveis epidurais craniais e caudais. Desenhos esquemáticos das vistas laterais, direita e esquerda, foram elaborados, para a descrição desses resultados. O crânio e os arcos das vértebras foram abertos e o encéfalo retirado sem a dura-máter.

A descrição das artérias e suas designações foram nominadas seguindo a Nomina Anatomica Veterinaria (1994), com o acréscimo de alguns termos, a critério dos autores, com base na literatura. A análise estatística dos resultados constou da aplicação do cálculo de porcentagem.

\section{RESULTADOS}

Os resultados da sistematização referemse às 30 peças injetadas com látex e, quando não especificados, correspondem a ambos os antímeros.

A artéria (A.) carótida comum, presente em $100 \%$ das preparações, ascendeu o pescoço e na altura da alça do nervo hipoglosso, medialmente ao processo paracondilar, dividiu-se em seus ramos terminais: as artérias carótidas interna e externa. Esta última foi a continuação natural do tronco principal (Figuras 1 e 2).

A A. carótida interna, ao curvar-se rostrodorsalmente, lançou caudodorsalmente a A. occipital em $100 \%$ dos casos. Emitiu, a seguir, uma fina artéria condilar, continuando-se medialmente à bolha timpânica, até alcançar a incisura carotídea, rostromedialmente, no forame lácero. Ao penetrar, transformou-se em inúmeros ramículos interligados, constituindo a rede admirável epidural rostral (RAER) (Figuras 1 e 2).

AA. occipital dirigiu-se para a fossa atlantal e, ao adentrar no forame alar, recebeu um ramo anastomótico caudal proveniente do estreito canal transversal do atlas. Esse vaso foi originado da A. vertebral, no espaço entre este e o áxis. AA. occipital, antes de ultrapassar o forame alar, emitiu dois ramos, que penetraram no forame vertebral lateral do atlas, formando a rede admirável epidural caudal (RAEC), sendo o primeiro deles levemente mais calibroso (Figura 1). A A. vertebral, além de ter emitido o ramo anastomótico para a A. occipital, lançou mais dois ramos, que penetraram no segundo espaço intervertebral: um contribuiu na formação da RAEC; outro se uniu à A. espinhal ventral.

A A. condilar originou-se da A. carótida interna em $100 \%$ das peças à direita e $93,3 \%( \pm 4,5)$ à esquerda; os restantes $6,7 \%( \pm 4,5)$ foram emitidos pela A. occipital. Quanto ao local de origem da A. condilar na A. carótida interna, foi identificada, em $60 \%( \pm 8,9)$ das peças à direita e 56,7\% $( \pm 9,1)$ à esquerda, alguns milímetros distais à origem da $\mathrm{A}$. occipital. Enquanto que em $40 \%( \pm 8,9)$ à direita $\mathrm{e}$ $36,6 \%( \pm 8,8)$ à esquerda, ao nível da emergência da A. occipital. A A. condilar dirigiu-se para a fossa condilar ventral, penetrou no canal do nervo hipoglosso, emergindo na cavidade craniana, dividiuse em ramos para a dura-máter e em dois segmentos que avançaram até o canal vertebral do atlas, através do forame magno, ligando-se à RAEC na totalidade das preparações.

Observando-se os dois moldes em acrílico percebeu-se que, em ambos os antímeros, a A. condilar, 


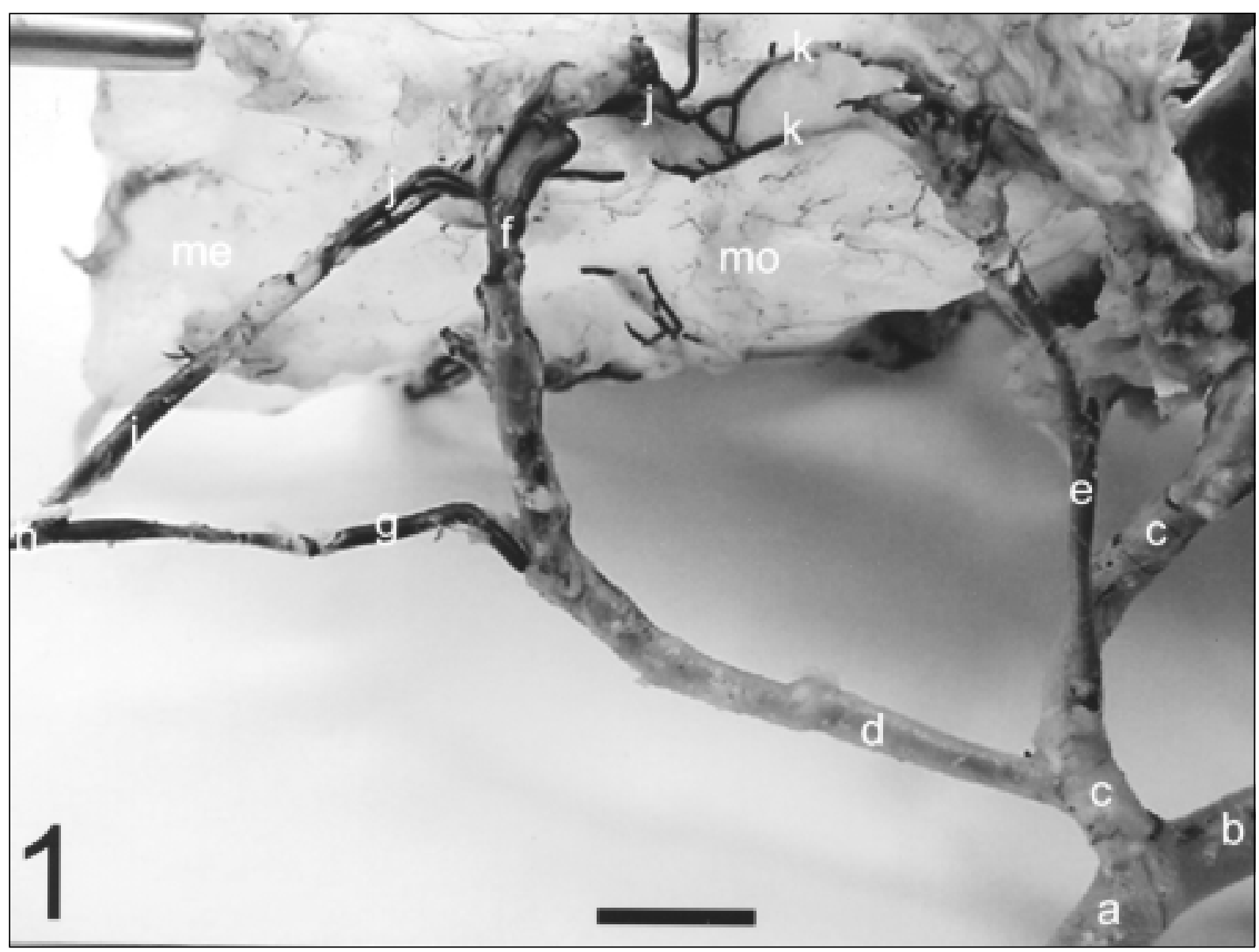

Figura 1 - Vista lateral direita das artérias que suprem a rede admirável epidural caudal (RAEC), retiradas da estrutura óssea: a- A. carótida comum; b- A. carótida externa; c- A. carótida interna; d- A. occipital; e- A. condilar; f- Ramos (dois) da A. occipital para a RAEC; g- Ramo anastomótico entre as artérias occipital e vertebral; h- A. vertebral; i- Ramo da A. vertebral para a RAEC; jRede admirável epidural caudal; k- Ramos da A. condilar para a RAEC; me,mo- Dura-máter da medula espinhal e da medula oblonga. Barra $=1 \mathrm{~cm}$.

pouco antes de alcançar a fossa condiliana, lançou um finíssimo ramo que adentrou pelo forame jugular, associando-se, na cavidade craniana, às ramificações da A. condilar para a dura-máter e RAEC, as quais penetraram pelo canal do nervo hipoglosso. Nas 30 peças injetadas com látex, esse ramo que atravessou o forame jugular, foi de difícil observação devido ao seu calibre reduzido e pela íntima relação do tronco principal com o nervo hipoglosso.

Como o objetivo do trabalho foi sistematizar as fontes de suprimento para as redes admiráveis epidurais rostral e caudal, consideraramse apenas os ramos colaterais principais das artérias: carótida externa e maxilar. A A. carótida externa projetou-se, rostralmente, emitindo as artérias lingual e facial, curvou-se medialmente ao colo da mandíbula, lançando a A. auricular caudal, originando, a seguir, um tronco para as artérias temporal superficial e transversa da face, continuando-se como A. maxilar. Esta última projetou-se rostralmente, dando origem, antes de atingir a crista pterigóide, às artérias alveolar mandibular e temporal profunda caudal, seguida da A. meníngea média (Figura 2).

A A. meníngea média dirigiu-se dorsomedialmente, lateral à bolha timpânica, penetrando na incisura espinhosa, rostrolateralmente, no forame lácero, acompanhando o nervo mandibular. Emitiu um fino ramo colateral, na maioria dos casos, para a RAER, distribuindo-se na dura-máter. Esta artéria, quando existente, foi encontrada como um vaso único em 15 casos à direita e 18 à esquerda, e aos pares, em 14 amostras à direita e 11 à esquerda.

Quando ímpar, emitiu um ramo colateral para a RAER e continuou, ramificando-se na dura- 


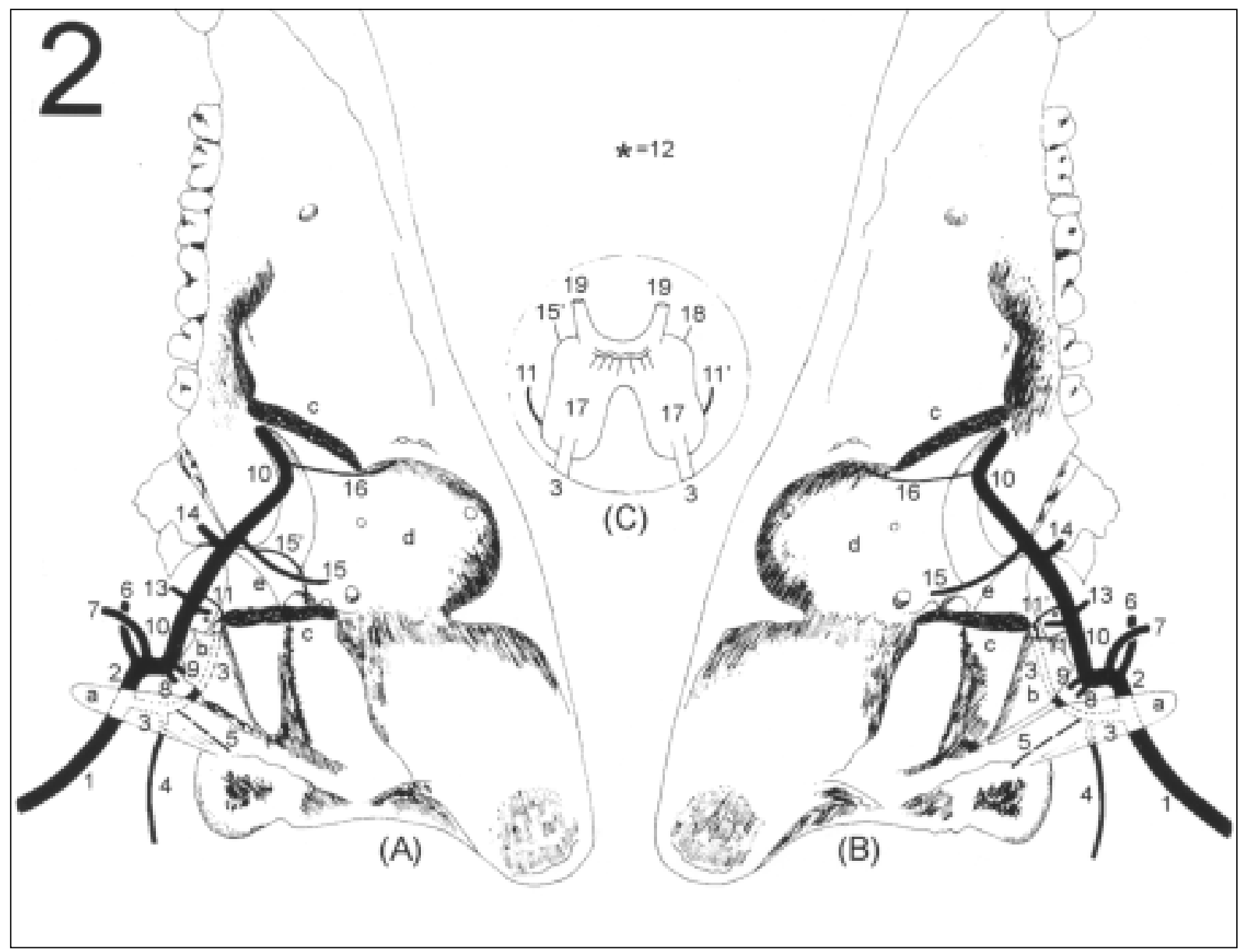

Figura 2 - Desenho esquemático das artérias que chegam ao crânio: A - Vista lateral esquerda, B - Vista lateral direita, C - Detalhe da rede admirável epidural rostral (RAER) em vista dorsal. 1- A. carótida comum; 2- A. carótida externa; 3- A. carótida interna; 4- A. occipital; 5- A. condilar; 6- A. lingual; 7- A. facial; 8- A. auricular caudal; 9- Tronco temporal superficial; 10- A. maxilar; 11- A. meníngea média; 11'- A. meníngea média acessória; 12- A. temporal profunda caudal; 13- A. alveolar mandibular; 14- A. bucal; 15- A. oftálmica externa; 15'- Ramo da A. oftálmica externa para a RAER; 16- A. malar; 17- Rede admirável epidural rostral; 18"Ramículos" da A. oftálmica externa para a RAER; 19- A. carótida do cérebro; a- Processo paracondilar; b- Bolha timpânica; cArco zigomático seccionado; d- Cavidade orbitária; e- Crista pterigóide. Redução de $50 \%$.

máter, exceto em um caso à esquerda, que não a alcançou, terminando-se na RAER. Nos casos de duplicidade, o vaso mais rostral correspondeu ao ramo da $\mathrm{A}$. meníngea média, que se dirigiu à RAER e foi designada pelos autores de "artéria meníngea média acessória". Nos casos de ausência da A. meníngea média, o seu território, correspondente para a dura-máter, foi suprido por um ramo calibroso originado diretamente da A. oftálmica externa.

A A. maxilar, antes de alcançar a fossa pterigopalatina, lançou a A. bucal rostroventralmente e, ao ultrapassar a crista pterigóide, emitiu, dorsocaudalmente, a A. oftálmica externa, continuando-se rostralmente até penetrar no forame maxilar, onde pouco antes emitiu a A. malar em todas as peças (Figura 2).

A A. oftálmica externa, ao alcançar a base de inserção do globo ocular, na cavidade orbitária, lançou caudalmente ramos para a dura-máter e RAER em $100 \%$ das preparações. Essa artéria esteve presente e ímpar em $70 \%( \pm 8,4)$ das amostras à direita e 73,3\% $( \pm 8,1)$ à esquerda, e dupla em $30 \%( \pm 8,4)$ dos casos à direita e $26,7 \%( \pm 8,1)$ à esquerda. Nos casos de duplicidade, o vaso mais rostral também emitiu ramos para a rede, e foi denominado pelos autores de "A. oftálmica externa acessória”. Quando ímpar, em 13 amostras à direita e 16 à esquerda, foram identificados apenas ramículos muito finos e delicados indo para a rede. No entanto, em 8 preparações à direita e 6 à 
esquerda, um ramo individualizado palpável, originado da A. oftálmica, foi identificado cooperando no suprimento da RAER. Tanto os ramículos como o ramo palpável penetraram no forame orbitário redondo, incorporados ao nervo maxilar (Figura 2).

$\mathrm{Na}$ amostra em que, bilateralmente, estava ausente a A. meníngea média, um ramo de maior calibre originou-se da A. oftálmica externa, dirigindo-se caudalmente, passando através do forame orbitário redondo, assumindo o território na dura-máter da A. meníngea média. Não foram observados sequer ramículos originados desses ramos para a RAER. Apenas um ramo similar ao caso anterior para a dura-máter, foi encontrado, à esquerda, na preparação em que a A. meníngea média supria apenas a RAER.

A rede admirável epidural rostral, no javali, foi formada nitidamente pelas artérias carótidas internas, com contribuição mínima complementar, por meio de ramos anastomóticos para a RAER, pelas artérias meníngea média, oftálmica externa e maxilar. As redes direita e esquerda interligaram-se na linha mediana, caudalmente à hipófise, através de um complexo emaranhado de vasos, dando a impressão de ser uma estrutura única. Seus contornos formaram a imagem de um "H", sendo perfeitamente visível, a cada lado da sela túrcica, a formação das artérias carótidas do cérebro pela reorganização dos vasos dessas redes (Figura 3 ).

Examinando-se, em vista dorsal, a malha da RAER, percebeu-se que essa era fina e constante na maioria das observações. Em 76,7\% $( \pm 7,7)$ das redes ficou evidente a formação de uma alça anastomótica, contornando a margem caudal da hipófise, para onde convergiam os vasos da parte anastomótica das redes (Figura 3A). Em 23,3\% ( \pm 7,7 ) das amostras não ocorreu a formação dessa alça, e a parte anastomótica apresentou-se como uma rede fina homogênea (Figura 3B). A RAER não apresentou qualquer comunicação anastomótica com a RAEC homolateral.

A rede admirável epidural caudal localizou-se ventrolateralmente à dura-máter, nas laterais da medula espinhal cervical próximo ao forame magno. Seu aspecto assemelhava-se a uma pequena rede plexiforme, com poucos vasos. A sua principal fonte de formação correspondeu a dois ramos provenientes da A. occipital, que penetraram pelo forame vertebral lateral do atlas. Cooperaram também em sua formação uma segunda fonte, os dois ramos da A. condilar, os quais chegaram rostralmente através do forame magno; e como terceira, um ramo da A. vertebral que chegou, caudalmente, através do forame vertebral lateral do áxis (Figura 1).

Da confluência da RAEC originou-se um ramo, o qual perfurou a dura-máter, na altura do nervo C , anastomosando-se com seu homólogo contralateral, na face ventral da medula oblonga, formando rostralmente a A. basilar. Pouco antes dessa disposição, cada ramificação recebeu uma contribuição anastomótica do ramo terminal da A. espinhal ventral em $86,7 \%( \pm 6,2)$ das peças, originando uma formação em "ilha". Entretanto, em 13,3\% ( $\pm 6,2)$ não ocorreu esse arranjo, pois a A. espinhal ventral não se bifurcou, desembocando diretamente na A. basilar.

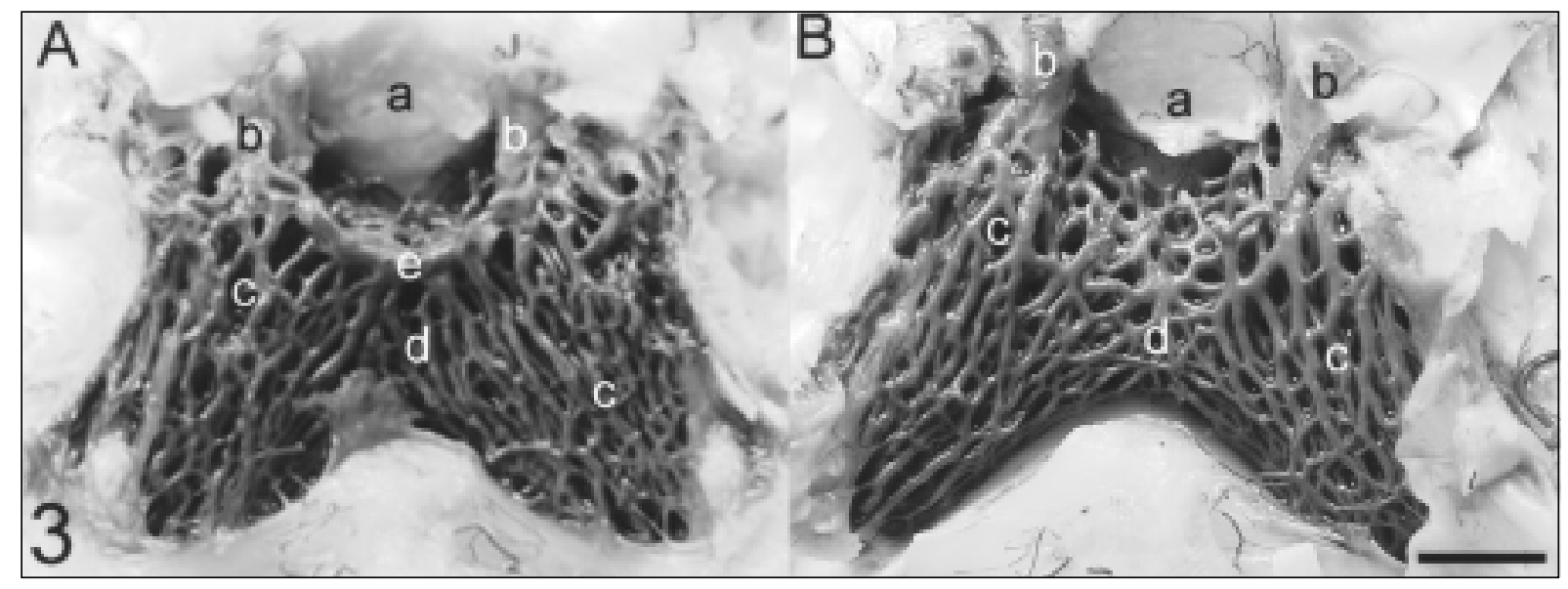

Figura 3 - Detalhe (vista dorsal) das redes admiráveis epidurais rostrais (RAER), após remoção da a dura-máter, para salientar as diferenças nos vasos anastomosantes: A - RAER com alça anastomosante (e); B - RAER sem alça anastomosante. a- Fossa hipofisária; b- A. carótida do cérebro; c- RAER esquerda e direita; d- ramos anastomóticos entre as RAERs. Barra $=0,5 \mathrm{~cm}$. 


\section{DISCUSSÃO}

$\mathrm{Na}$ revisão da literatura, a maioria dos autores descreve a formação das redes admiráveis epidurais apenas em suínos, somente JABLONSKI et al. (1989) fazem poucas referências à constituição das redes no javali. Segundo BOURDELLE \& BRESSOU (1964), a artéria (A.) carótida primitiva lança três ramos desiguais, as artérias: occipital, carótida interna e carótida externa. Já para GHOSHAL (1981), a A. carótida comum termina de modo variável nas artérias carótida externa, occipital e carótida interna, frisando, em seguida, que essa última surge de um tronco comum com a A. occipital.

Em nossos resultados, descrevemos a $\mathrm{A}$. occipital como um ramo colateral da A. carótida interna. Essa se mostrou como a continuação natural do vaso inicial originado da A. carótida comum, sendo que a A. occipital foi visivelmente um ramo colateral de menor calibre. A A. carótida interna penetra na cavidade craniana pelo orifício carotidiano no hiato rasgado anterior (forame lácero) terminando-se por uma rede admirável, sendo exclusivamente destinada à circulação cerebral (BOURDELLE \& BRESSOU, 1964; GHOSHAL \& KHAMAS, 1985). Coincidindo com nossos achados e contrariando DANIEL et al. (1953), McCLURE \& DELLMANN (1965), GILLILAN (1974) e McGRATH (1977), os quais citam a A. faríngea ascendente como principal formadora da rede, referindo-se que a A. carótida interna está ausente e apenas persiste a porção intracraniana, a qual se estende da rede até o círculo de Willis (círculo arterial cerebral).

A A. faríngea ascendente foi denominada por alguns autores como porção extracranial da A. carótida interna e ramo para a rede epidural rostral pela Nomina Anatomica Veterinaria de 1983 (GHOSHAL \& KHAMAS, 1985). Nesta pesquisa, a A. faríngea ascendente não foi estudada, entretanto a Nomina Anatomica Veterinaria de 1994 e SCHALLER (1999) citam a A. faríngea ascendente como ramo da A. lingual e designam o vaso que se estende da A. carótida comum até a rede admirável epidural rostral (RAER) como A. carótida interna.

Em relação às outras fontes que cooperam na formação da RAER, para DANIEL et al. (1953) o fluxo sanguíneo para a rede deriva também da A. anastomótica (ramo para a rede da A. oftálmica externa) e do ramo anastomótico (A. meníngea média). Esses autores relatam ainda que o ramo anastomótico, em outros artiodáctilos, é um grande vaso que conecta a A. maxilar interna (maxilar) com a rede carótida (RAER), emitindo ainda pequenos ramos para suprir as meninges. No suíno, ao contrário, o vaso principal dirige-se para as meninges e a parte para a rede está representada por um ramo muito pequeno.

Segundo BOURDELLE \& BRESSOU (1964); GHOSHAL (1981); GHOSHAL \& KHAMAS (1985) e FERREIRA (1998), as artérias meníngea média e oftálmica externa emitem finos ramos anastomóticos para a RAER. GHOSHAL \& KHAMAS (1985) informam ainda que, em poucos casos, o ramo meníngeo para a rede origina-se diretamente da A. maxilar.

Considerando-se de forma genérica, os resultados obtidos são coincidentes com esses autores, uma vez que, em nossos achados, a RAER foi formada, basicamente, pela A. carótida interna, com contribuição de ramos oriundos das artérias meníngea média e oftálmica externa e, em algumas peças, por ramos provenientes diretamente da $\mathrm{A}$. maxilar. Nos casos de duplicidade da A. meníngea média, denominamos de "A. meníngea média acessória" o vaso originado diretamente da A. maxilar, o qual supriu a parte do território permanente da A. meníngea média. A presença de um vaso com origem e distribuição semelhante ao da A. meníngea média acessória foi referido por GHOSHAL \& KHAMAS (1985) em poucos casos.

A distribuição dos ramos da A. meníngea média, em suínos (DANIEL et al., 1953) está de acordo com nossos achados. A presença de uma "A. oftálmica externa acessória" não foi referida por nenhum autor. Esta denominação, por nós utilizada, baseou-se no mesmo critério observado em relação a "A. meníngea média acessória”, uma vez que era um vaso o qual supria, individualmente, a parte do território que sempre pertenceu à A. oftálmica externa.

A RAER foi descrita como uma malha de finas arteríolas (DANIEL et al., 1953; BOURDELLE \& BRESSOU, 1964; NANDA, 1981), de formato oval, situada a cada lado da hipófise (DANIEL et al., 1953; BOURDELLE \& BRESSOU, 1964). De acordo com DANIEL et al. (1953) e GILLILAN (1974), os vasos de cada lado da rede conectam-se livremente com o outro lado no bordo medial. Enquanto para NANDA (1981), as mesmas estão interligadas por uma formação plexiforme interanastomosante no interior do seio intercavernoso.

Os relatos gerais da RAER no suíno coincidem em vários aspectos da descrição. Porém, além de determinarmos a forma de " $\mathrm{H}$ " no conjunto, percebemos, na maioria dos casos, a presença de um vaso em forma de alça junto à porção anastomótica, achado este não relatado em nenhuma descrição. 
Da extremidade rostral da RAER, pela reunião dos vasos da rede, parte um tronco que perfura a dura-máter e une-se ao círculo arterial cerebral, vaso esse denominado de A. carótida interna (DANIEL et al., 1953; GILLILAN, 1974; NANDA, 1981; GHOSHAL \& KHAMAS, 1985). JABLONSKI et al. (1989), estudando o javali, relatam apenas que a A. carótida interna é formada a partir da RAER, e depois, de perfurar a dura-máter, alcança a base do cérebro, atrás da borda posterior do nervo óptico, onde se divide. FERREIRA (1998), em suínos, a designa de "A. carótida do encéfalo", e foi por nós denominada de "A. carótida do cérebro". Essa foi assim denominada para que houvesse distinção entre seu segmento proximal, antes da rede, de seu segmento distal, após esta.

Com relação à rede admirável epidural caudal (RAEC), apenas em tratados mais recentes foram encontradas descrições, mesmo assim, as informações sobre suas fontes supridoras revelaram muitas contradições. Para GILLILAN (1974), a A. basilar continua-se na A. espinhal mediana anterior (espinhal ventral). Segundo este autor, não existem artérias vertebrais intracraniais verdadeiras no suíno. Ocasionalmente, uma pequena artéria medular entra no canal espinhal, acompanhando o primeiro nervo cervical, unindo-se com o final da artéria basilar.

A A. vertebral do suíno, ao atravessar a fossa atlantal, anastomosa-se com a A. occipital. Segue através do forame alar e vertebral lateral para o interior do canal vertebral, unindo-se a RAEC e continuandose para formar a A. basilar, ao ligar-se com a A. vertebral do lado oposto (GHOSHAL, 1981 e NANDA, 1981).

Para GHOSHAL \& KHAMAS (1985), a RAEC recebeu o suprimento sanguíneo da porção terminal da A. vertebral e de seu ramo espinhal, da A. condilar e, ocasionalmente, da A. occipital. JABLONSKI et al. (1989), estudando o javali, não se referem à RAEC, citando apenas que a A. vertebral, após perfurar a dura-máter, percorre a superfície ventral da medula oblonga, onde se associa à $\mathrm{A}$. vertebral contralateral, originando a A. basilar. Já para FERREIRA (1998), a A. occipital de ambos os antímeros forma, rostralmente, a A. basilar, e caudalmente a A. espinhal ventral, na altura do atlas.

Contradizendo a maioria dos autores, em nossos achados, a principal fonte de formação da RAEC originou-se de dois ramos da A. occipital, sendo que a A. occipital recebeu um ramo anastomótico, proveniente da A. vertebral, na altura do forame alar. O segundo componente foram dois ramos, oriundos da A. condilar, e ainda uma terceira fonte, um ramo da A. vertebral.
Em nossas observações, da RAEC partiu um ramo, que perfurou a dura-máter, unindo-se com seu homólogo contralateral, formando a A. basilar rostralmente. Como a RAEC é um pequeno plexo, poderia ter dado a impressão de que o ramo direto da A. occipital (FERREIRA, 1998) ou da A. vertebral, relatado pelos demais autores, formaria a A. basilar. Conforme GHOSHAL (1981), a A. occipital emite a A. condilar, que às vezes é dupla. Esta se divide na fossa condilar ventral, e uma de suas divisões penetra na cavidade craniana através do forame do hipoglosso, enquanto que o outro ramo adentra pelo forame jugular, contribuindo para a RAEC. Nos moldes em acrílico, observamos um fino ramículo da $\mathrm{A}$. condilar, que penetrou no forame jugular. Nas peças injetadas com látex, esse foi de difícil observação, devido ao calibre e por estar associado ao nervo hipoglosso em sua origem.

Neste estudo, a A. condilar foi um vaso único originado da A. carótida interna, e em apenas dois casos foi emitida pela A. occipital, contrariando GHOSHAL (1981), que a relata como sempre sendo uma ramificação da A. occipital, e concordando com GHOSHAL \& KHAMAS (1985), que a encontraram como divisão da A. carótida interna. Entretanto, esses autores relatam ocasionalmente a presença de duplicidade.

\section{CONCLUSÕES}

As fontes que formaram as redes admiráveis epidurais rostrais foram principalmente as artérias carótidas internas, em 100\% dos casos, com uma fraca colaboração dos ramos anastomóticos para a rede das artérias meníngea média, oftálmica externa e maxilar.

A rede admirável epidural caudal foi formada pelos dois ramos da a. occipital, lateralmente; dois ramos da a. condilar, rostralmente, e um ramo da a. vertebral, caudalmente.

As artérias carótidas internas foram a principal fonte supridora das redes admiráveis, direta ou indiretamente, uma vez que a rede rostral foi formada basicamente pela A. carótida interna, enquanto que a caudal originou-se principalmente de seus ramos occipital e condilar. A A. vertebral teve uma mínima cooperação na formação da RAEC.

\section{FONTES DE AQUISIÇÃO}

\footnotetext{
a Heparin - Cristália Produtos Químicos Farmacêuticos Ltda., Itapi, SP.

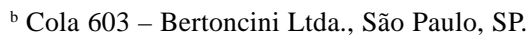

c Suvinil corante - BASF S.A., São Bernardo do Campo, SP.

d Jet incolor - Artigos Odontológicos Clássico Ltda, São Paulo, SP.
} 
e Orto íris - Artigos Odontológicos Clássico Ltda, São Paulo, SP.

\section{REFERÊNCIAS BIBLIOGRÁFICAS}

BOURDELE, E.; BRESSOU, C. Anatomie régionale des animaux domestiques, III - le porc. 2.ed. Paris : Baillière et fils, 1964. $378 \mathrm{p}$.

DANIEL, P.M.; DAWES, J.D.K.; PRICHARD, M.M.L. Studies of the carotid rete and its associated arteries. Philosophical Transactions of the Royal Society, London, Ser. B. v.237, p.173208, 1953.

FERREIRA, C.G. Estudo anatômico das artérias da base do encéfalo de suínos (Sus scrofa domesticus, LINNAEUS, 1758). 1998. 98f. Dissertação (Mestrado em Anatomia de Animais Domésticos) - Programa de Pós-graduação da Faculdade de Medicina Veterinária e Zootecnia, Universidade de São Paulo.

GHOSHAL, N.G. Coração e artérias do suíno. In: GETTY, R. Sisson/Grossman anatomia dos animais domésticos. 5.ed. Rio de Janeiro : Interamericana, 1981. V.2, p.1226-1232.

GHOSHAL, N.G.; KHAMAS, W.A.H. Gross and histomorphological estudy on the rostral epidural rete mirabile of the pig. Indian Journal of Animal Sciences, New Delhi, v.55, n.5, p.304-310, 1985.
GILLILAN, L.A. Blood supply to brains of ungulates with and without a rete mirabile caroticum. Journal Comparative Neurology, Philadelphia, v.153, p.275-290, 1974.

INTERNATIONAL COMMITEE ON VETERINARY GROSS ANATOMICAL NOMENCLATURE. Nomina anatomica veterinaria. 4.ed. New York, 1994. 59p.

JABLONSKI, R.; BRUDNICKI, W.; WILAND, C. Basilar arteries of the brain in wild boar. Acta Theriologica, Warszana, v.34, n.11, p.159-162, 1989.

McClURE, R.C.; DELLMANN, H.D. The blood supply to the cerebral rete mirabile and its nomenclature in the pig (Sus scrofa). Anatomical Record, Philadelphia, v.115, p.384, 1965 .

McGRATH, P. Observations on the intracranial carotid rete and the hypophisis of mature pig and sheep. Journal of Anatomy, Londres, v.124, n.3, p.689-699, 1977.

NANDA, B.S. Suprimento sangüíneo para o cérebro. In: GETTY, R. Sisson/Grossman anatomia dos animais domésticos. 5.ed. Rio de Janeiro : Interamericana, 1981. V.2, p.1232-1237.

SCHALLER, O. Nomenclatura anatômica veterinária ilustrada. Rio de Janeiro : Manole, 1999. p.242-283. 